\title{
Effect of Gravity on Arc Shape in GTA Welding*
}

\author{
by Yasuhiro AOKI**, Hidetoshi FUJII** and Kiyoshi NOGI**
}

\begin{abstract}
In order to investigate the effect of gravity on the arc shape in gas tungsten arc (GTA) welding, GTA welding was carried out using the drop-shaft type microgravity system at the Japan Microgravity Center (JAMIC). The materials used were an aluminum alloy and pure silver. It has became clear that the effect of gravity on the arc shape is not observed under general welding conditions (over $70 \mathrm{~A}$ ) regardless of the observed region and the shielding gas flow rate. The displacement of the arc gap during the transition from the terrestrial environment to the microgravity environment can change the arc shape.
\end{abstract}

Key words: gas tungsten arc welding, microgravity, arc shape, aluminum alloy.

\section{Introduction}

An arc is the heat source of the arc welding processes, and its condition significantly affects the welding phenomena and the condition of the final product. Accordingly, arc shapes under several conditions have been observed by many researchers ${ }^{1-5}$, and the results have provided valuable information on the plasma phenomena in the arc. For example, Nishiguchi et al. ${ }^{11}$ observed arc shapes at low pressure argon atmosphere in gas tungsten arc (GTA) welding and clarified the relationship between the cathode plasma zone and the pressure level. Matsunawa et al ${ }^{2}{ }^{2}$ observed arc shapes at high pressure argon atmosphere in GTA welding as well as gas metal arc (GMA) welding and found that the current density at the electrode tip increased in GTA welding and was suppressed in GMA welding. Muller ${ }^{3)}$ and Finkelnburg ${ }^{4)}$ pointed out the arc stiffness in GMA welding and in carbon arc welding, respectively. Key ${ }^{5}$ assessed the relationship between the shielding gas composition and the electrode geometry in GTA welding.

The authors have investigated the gravitational effect by observing the arc shapes both in a microgravity environment and in a terrestrial environment ${ }^{6}$. The arc shapes were found to be very similar in both environments. Kaihara et al..$^{7}$ and Abe et al. ${ }^{8)}$ reported that gravity did affect the arc shape in spite of similar current conditions $(60-100 \mathrm{~A})$. Accordingly, in this study, in order to investigate the effects of shielding gas flow rate, arc current, arc gap and the observed region in detail, the arc shapes in a microgravity environment and in a terrestrial environment are compared under various conditions.

\section{Experimental}

In this study, gas tungsten arc (GTA) welding was performed both in a microgravity environment and in a terrestrial environment, and the arc shapes in both environments were observed and compared. The GTA welding process uses a nonconsumable tungsten electrode and can avoid the fusible electrode transfer in the arc. Accordingly, the welding process has a great advantage in the observation of the arc shape compared with the other arc welding processes. A microgravity condition was obtained using the free fall system at the Japan Microgravity Center. The system can maintain a $10 \mathrm{~s}$ microgravity of less than $10^{-5} \mathrm{G}$. The GTA welding apparatus used in this study consists of a welding chamber, a battery, a welding power source, a shielding gas supply and a welding control system, as shown in Figure 1. The welding chamber is equipped with a specimen and a torch sliding system. In this study, several CCD cameras with different transmissivity filters were used in order to observe both regions of the arc core and the arc flame simultaneously. The battery is an uninterruptible power system (UPS) which supplies $2.4 \mathrm{~kW}$ $(\mathrm{ACl} 100 \mathrm{~V}, 3000 \mathrm{VA})$ to the welding power source.

The material selected was an aluminum alloy A2219 because it is commonly used in the aerospace industry.

\footnotetext{
*Received:

**Osaka Univ., Joining and Welding Research Institute
} 
Table 1 Chemical composition of $\mathrm{Al}-\mathrm{Cu}$ alloy A2219, mass\%

\begin{tabular}{cccccccccccc}
\hline $\mathrm{Al}$ & $\mathrm{Si}$ & $\mathrm{Fe}$ & $\mathrm{Cu}$ & $\mathrm{Mn}$ & $\mathrm{Mg}$ & $\mathrm{Cr}$ & $\mathrm{Zn}$ & $\mathrm{Ti}$ & $\mathrm{Zr}$ & $\mathrm{Pb}$ & $\mathrm{V}$ \\
\hline $\mathrm{Bal}$ & 0.07 & 0.16 & 6.26 & 0.30 & - & - & 0.01 & 0.04 & 0.18 & 0.01 & 0.09 \\
\hline
\end{tabular}

Table 2 Welding conditions.

\begin{tabular}{l|cc}
\hline sample & A2219 & Silver \\
\hline welding current (A) & 80 & 71 \\
welding voltage (V) & 12 & 16 \\
welding speed (m/s) & $3.6 \times 10^{-3}$ & $4.0 \times 10^{-3}$ \\
shielding gas flow rate $\left(\mathrm{m}^{3} / \mathrm{s}\right)$ & $8.3 \times 10^{-5}$ & 0 \\
arc length (m) & $2.0 \times 10^{-3}$ & $3.0 \times 10^{-3}$ \\
\hline
\end{tabular}

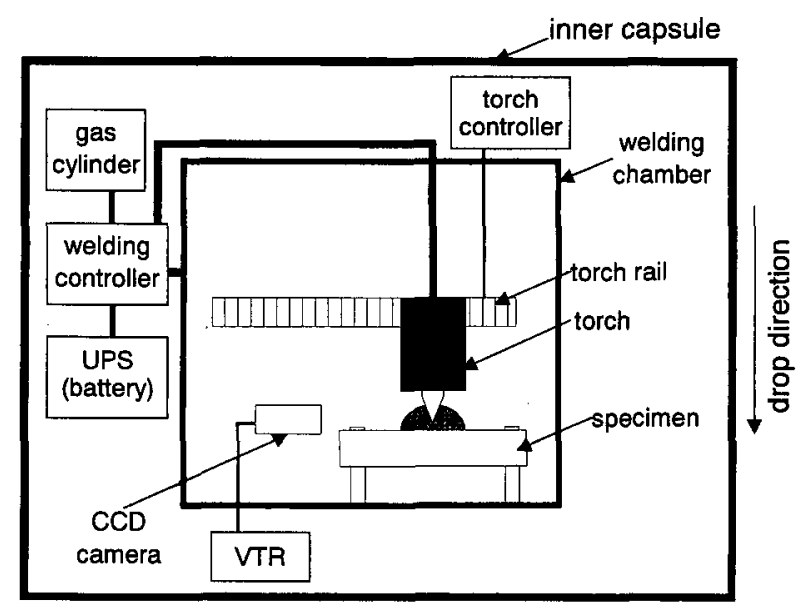

Fig. 1 Schematic diagram of GTA welding apparatus.

Table 1 shows the chemical composition of the aluminum alloy. For aluminum alloys, the anode spot often moves discontinuously due to the distribution of the oxide layer on the surface ${ }^{9}$. To avoid the arc movement, pure silver ( 99.99 mass\%) was also used. The size of the samples is $100 \mathrm{~mm}^{l} \times 50 \mathrm{~mm}^{w} \times 3 \mathrm{~mm}^{t}$. Table 2 shows the welding conditions. The welding current was $70-80 \mathrm{~A}$. It was set a small value in the range of general welding operations. The shielding and atmospheric gases were argon (99.9995\% in purity). Bead-on-plate welding was performed with the flat welding position. The polarity was direct current electrode negative (DCEN) in order not to consume the electrode. The electrode was made of a $2 \%$-thoriated-tungsten and its diameter was $1.6 \mathrm{~mm}$ with a $30 \mathrm{deg}$ tip angle. In this study, careful attention was also paid to the arc gap in both environments being the same.

\section{Results and Discussion}

\subsection{Observed Region}

An arc is generally compressed by the electromagnetic force due to the current flowing in the arc. This phenomenon is called the electric pinch effect ${ }^{3,4,10, \text { and } 111}$. The effect is larger in the arc core region, because the temperature and the current density are higher there. Accordingly, it seems that the arc core region will not easily be affected by gravity. The surroundings of the arc core, that is, the arc flame, on the other hand, may be affected by gravity. Thus, when a different part of the arc is measured, a different result might be obtained. In this study, several optical filters with different transmissivity were used to observe both regions of the arc.

Figure 2 shows the appearance of the high temperature region, that is, the arc core, observed through a welding filter (JIS 11). The transmissivity of the filter is 0.005 in the visible range. Figure 3 shows the surroundings of the arc core, that is, the arc flame, observed through an ND filter. The transmissivity is 0.03 . Tanaka et al. reported that the electric pinch effect was negligible when the position was $1.5 \mathrm{~mm}$ far from the center under conditions of welding current; 50-150 A, arc gap ; $5 \mathrm{~mm}$, electrode diameter; $3.2 \mathrm{~mm}$, tip angle ; 60 degree ${ }^{12)}$. Accordingly, the electric pinch effect should be negligible in the arc frame shown in Fig. 3. As shown in Figs. 2 and 3, the shapes of the arc core and the arc flame in both environments are almost the same. No 
(a) $1 \mathrm{G}$

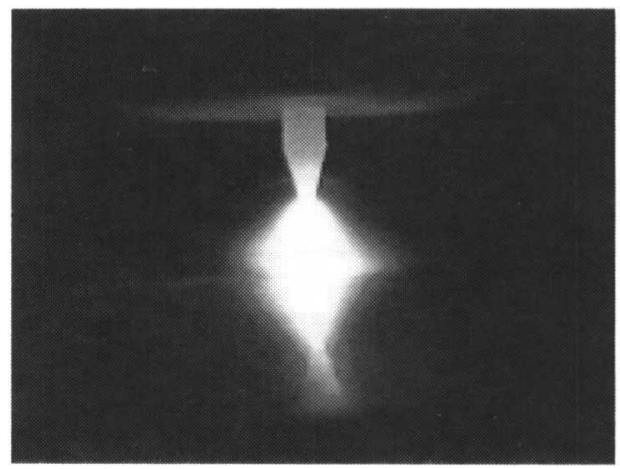

(b) $10^{-5} \mathrm{G}$

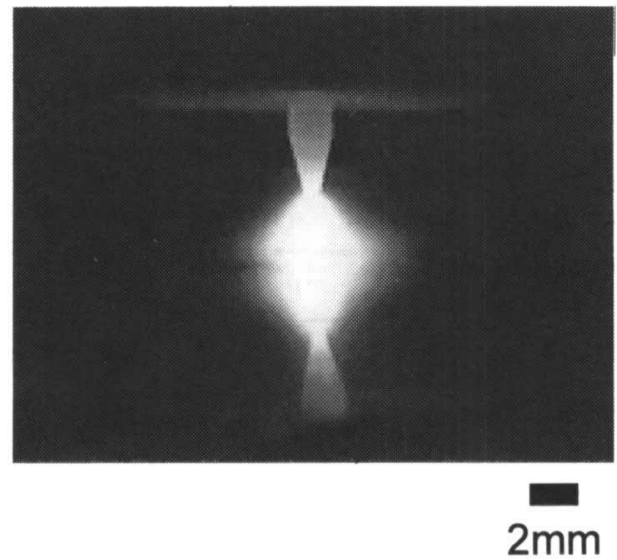

Fig. 2 Appearances of high temperature region (arc core) observed through welding filter (JIS 11) in both environments.

(a) $1 \mathrm{G}$

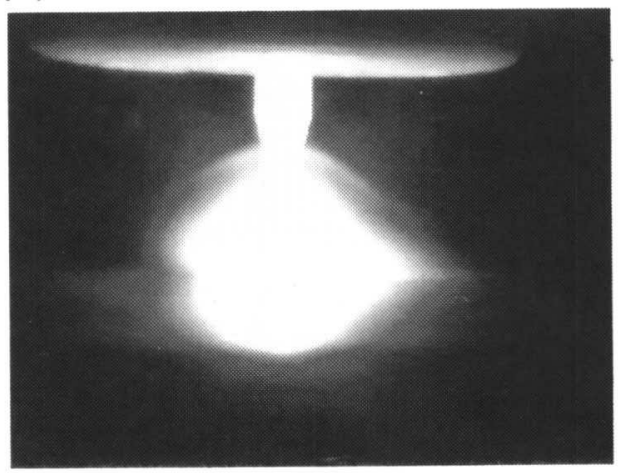

(b) $10^{-5} \mathrm{G}$

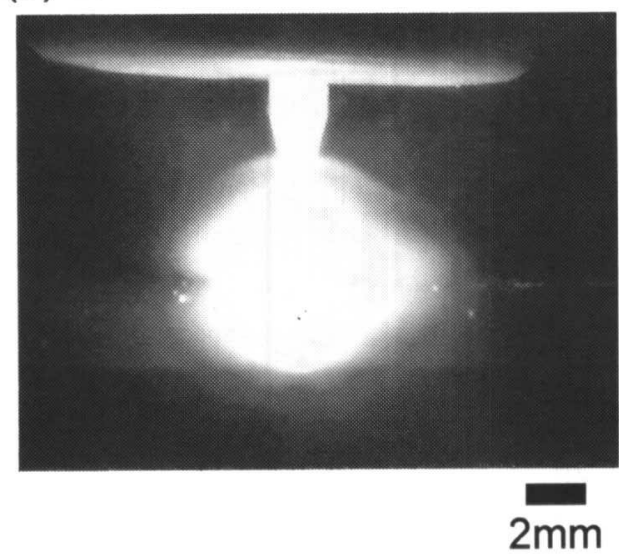

Fig. 3 Appearances of low temperature region (arc fiame) observed through ND filter in both environments.

(a) $1 \mathrm{G}$

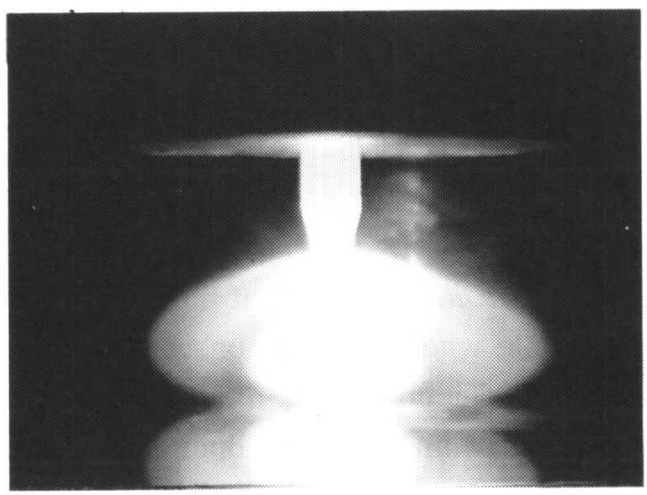

(b) $10^{-5} \mathrm{G}$

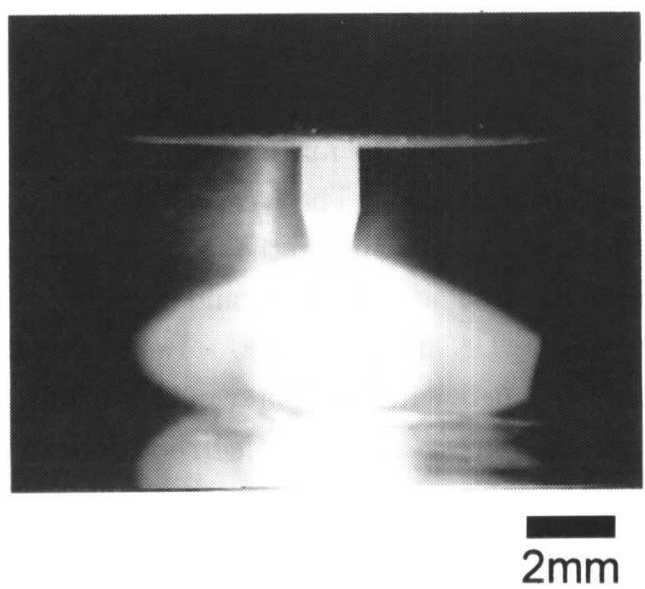

Fig. 4 Arc shape images without shielding gas observed through ND filter in both environments. 
effect of gravity is observed in both high temperature and low temperature regions.

\subsection{Flow rate of shielding gas}

The results in section 3.1 were also obtained with argon shielding gas flowing at a rate of $8.3 \times 10^{-5} \mathrm{~m}^{3} / \mathrm{s}^{6}$. In these cases, the arc shapes were very similar in both environments. When the shielding gas flows around the arc, the arc may be stabilized by a stable shielding gas flow around the arc. In this study, in order to investigate the effect of shielding gas on the arc, welding was performed in an argon atmosphere without shielding gas flowing, in both environments. When no shielding gas flows for aluminum alloys, the arc is usually unstable due to the discontinuous movement of the anode spot because the thermal pinch effect decreases. In this study, silver was chosen for the experiments in order to estimate the effect of gravity precisely. The welding current is also reduced in order not to form a weld pool so that the effect of the pool could be reduced.

Figure 4 shows arc shape images without a shielding gas in both environments. In this case, an ND filter with 0.05 transmissivity was used. The arc shapes were very similar in both environments, though the arc shape in the microgravity environment was less stable. Thus, no effect of gravity on the arc shape was observed regardless of the shielding gas flow rate.

\subsection{Arc gap}

A possible reason for the change in the arc shape is the displacement of the arc gap during the transition from the terrestrial to the microgravity environment. Figure 5 and 6 show the change in the arc shape and the arc voltage during the transition from under a terrestrial condition to under a microgravity condition, respec- (a) before transition (1G)

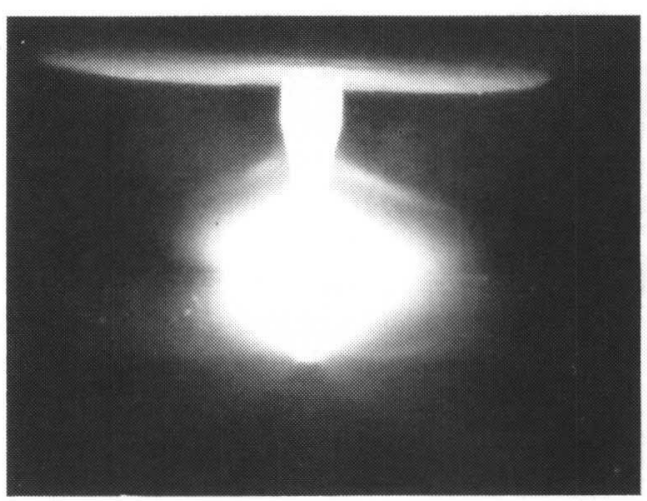

(b) after transition $\left(10^{-5} \mathrm{G}\right)$

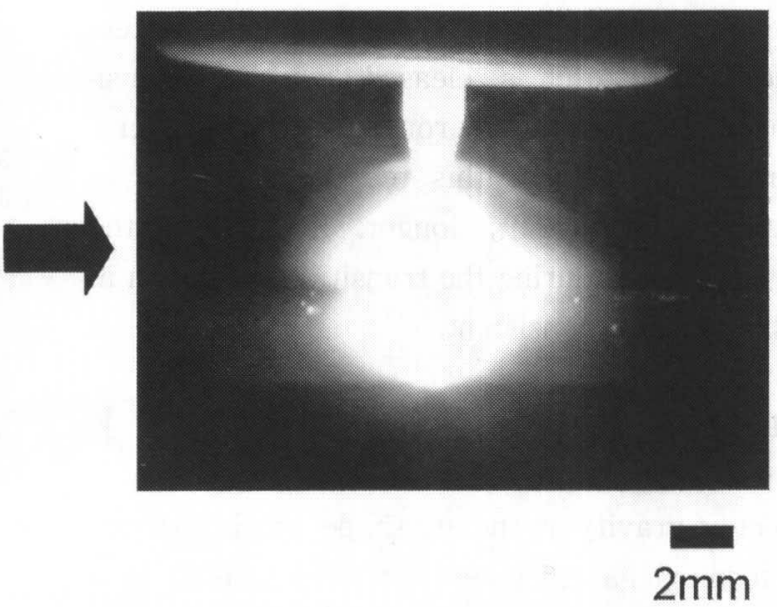

(c) Schematic illustration of change in arc shape during transition

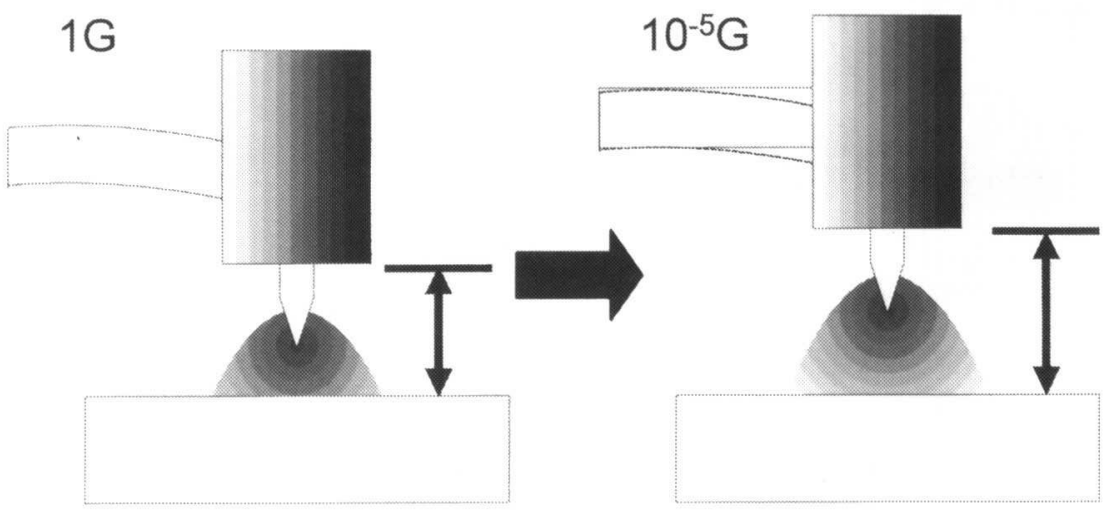

Fig. 5 Change in arc shape during transition from terrestrial environment to microgravity environment. 


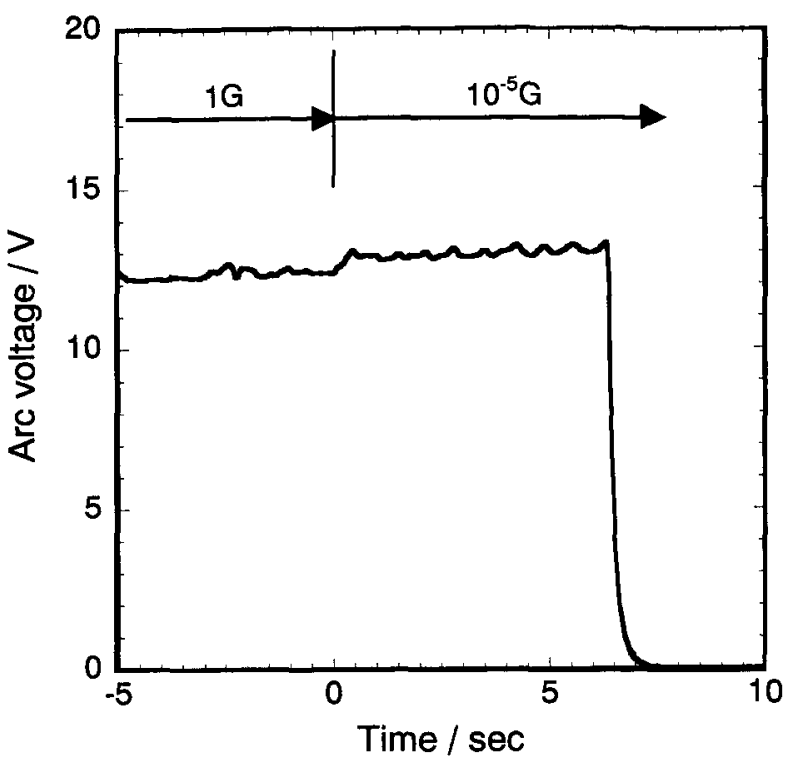

Fig. 6 Change in arc voltage during transition from terrestrial environment to microgravity environment.

tively. As shown in Fig. 5, the arc shape in the microgravity environment is larger than that in the terrestrial environment. In the microgravity experiment, the tension of the welding torch is released during the transition from the terrestrial environment to the microgravity environment. For this reason, the arc gap becomes about $0.6 \mathrm{~mm}(20 \%)$ longer. In this case, the arc voltage increases during the transition, as shown in Fig. 6. This result is consistent.

\section{Conclusions}

The effect of gravity on the arc shape was investigated by performing gas tungsten arc welding both in a terrestrial environment and a microgravity environment. As a result, the following conclusions were achieved.

(1) In both the high temperature and the low temperature regions, that is, in the arc core region and in the arc flame region, no effect of gravity is observed under general welding conditions (over $70 \mathrm{~A}$ ) regardless of the shielding gas flow rate.

(2) The displacement of the arc gap during the transition from the terrestrial environment to the microgravity environment can change the arc shape.

\section{Acknowledgments}

The authors greatly appreciate the support from the Japan Space Utilization Promotion Center (JSUP), the Japan Microgravity Center (JAMIC) and the Japan Space Forum.

\section{References}

1) K. Nishiguchi, T. Yamamoto and W. Shimada, IIW Document 212-204-71 (1971).

2) A. Matsunawa and K. Nishiguchi, in Arc Physics and Weld Pool Behavior, The Welding Institute, 1, p. 123. (1979).

3) A. Muller, W.J. Greene and G R. Rothschild, J. A. W. S., 30, 717 (1951).

4) W. Finkelnburg, Z. Phys., 112, 305 (1937).

5) J.F. Key, Weld. J. 59, 365s (1980).

6) K. Nogi, Y. Aoki, H. Fujii, K. Nakata, and S. Kaihara, ISIJ Int., 38, p. 163. (1998).

7) S. Kaihara, M. Kuribayashi, A. Tanji, K. Kawachi, and K. Nezaki, Ishikawajima-Harima Tech. Rev., 34, 109 (1994).

8) Y. Abe, C. Yasuda, M. Fujiwara, M. Nayama, and H. Okazaki, Mitsubishi Juko Tech. Rev., 27, 532 (1990).

9) K. Ando and J. Nishikawa, J. J. W. S., 30, 700 (1961).

10) K. Ando and M. Hasegawa, in Welding Arc Phenomena, Sanpo Inc., p. 162. (1968).

11) K. Ando and M. Hasegawa, in Welding Arc Phenomena, Sanpo Inc., p. 172. (1968).

12) K. Tanaka and M. Ushio, J. Phys. D : Appl. Phys, 32, 1153 (1999). 